\title{
La identidad muchik en Lambayeque, Perú: continuidad cultural, etnogénesis y etnicidad
}

\author{
The muchik identity in Lambayeque, Peru: \\ cultural continuity, ethnogenesis and ethnicity \\ Javier Expósito Martín \\ Universidad Complutense de Madrid-ESPAÑA \\ javierexpositomartin2018@gmail.com
}

\section{Resumen}

Actualmente existe un intenso debate acerca del rescate de la cultura mochica, del proceso de construcción de una identidad colectiva muchik y de su auto-reconocimiento por parte de la población de Lambayeque (Perú). En las últimas décadas, por un lado, se ha dado un discurso identitario promovido por los arqueólogos más prestigiosos junto a las élites comerciales y políticas lambayecanas, y por otro, un discurso defendido por antropólogos y dirigentes locales. El objetivo de esta investigación, a través de una serie de entrevistas a especialistas e informantes relevantes, es realizar una revisión, análisis y reevaluación del proceso de construcción de la identidad muchik, para establecer la existencia o no de un continuum cultural muchik en Lambayeque y el grado de autoadscripción presente en su población, además de verificar si existe un proceso de etnicidad y de etnogénesis.

Palabras clave: identidad, muchik, Lambayeque, etnogénesis, etnicidad

\begin{abstract}
Currently there is an intense debate about the rescue of Mochica culture, the process of building a collective identity muchik and its self-recognition by the population of Lambayeque (Peru). In recent decades, on the one hand, there has been an identity discourse promoted by the most prestigious archaeologists alongside the commercial and political elites of Lambayecan, and on the other, a speech defended by anthropologists and local leaders. The objective of this research is, through a series of interviews with relevant specialists and informants, to conduct a review, analysis and reassessment of the process of building muchik identity, to establish the existence or not of a cultural continuum muchik in Lambayeque and the degree of self-registration present in its population, in addition to verifying whether there is a process of ethnicity and ethnogenesis.
\end{abstract}

Javier Expósito Martín

La identidad muchik en Lambayeque, Perú: continuidad cultural, etnogénesis y etnicidad Autoctonía. Revista de Ciencias Sociales e Historia, Vol. IV, N 1 , Enero-Junio 2020, 113-133 ISSN 0719-8213

DOI: http://dx.doi.org/10.23854/autoc.v4il.124 
Key words: identity, muchik, Lambayeque, ethnogenesis, ethnicity

Recibido: 05 de Julio de 2019 • Aceptado: 19 de Diciembre de 2019

\section{Discursos de identidad muchiken Lambayeque}

Desde hace más de cuatro décadas, en Lambayeque se está desarrollando un proceso de construcción identitaria cuyo núcleo central es el rescate y la revitalización de la cultura mochica ${ }^{1}$. Anteriormente, nunca se había dado un proceso identitario tan fuerte, “ya que esta región había carecido de referentes propios" (Alva Meneses, comunicación personal, enero de 2017) y se percibía a sí misma, como de segunda categoría frente a la gran cultura incaica del pasado y, a la actual "todo poderosa" ciudad de Lima. Debido a este fenómeno que se vive en Lambayeque, ha surgido, en parte de la población, una concientización por valorar su pasado prehispánico; ahora se perciben como los descendientes de una gran civilización y de una prominente cultura: la mochica, equiparable a la incaica. A raíz de ello, se ha desarrollado un sentimiento de pertenencia a una identidad colectiva, en una parte de la población Lambayecana.

La identidad es una construcción sociocultural sobre la cual se agrupan individuos que comparten rasgos culturales, costumbres, valores y creencias. La identidad no es un concepto fijo, sino cambiante, por ello, los procesos de construcción de la identidad colectiva están "relacionados con estos cambios y con la interacción de unos individuos con otros, en un mundo que es histórico" (Mercado y Hernández, 2010: 231).
No puede existir identidad cultural sin la memoria, "sin reconocer el pasado aunque sea a través de elementos simbólicos que suponen un referente y ayudan a construir el futuro. Tampoco es posible manifestar una identidad, sino a partir del patrimonio cultural, que existe de antemano, independientemente de su valoración o reconocimiento" (Molano, 2007: 78).

La identidad es hacerse consciente de un pasado común, es reconocer y apropiarse de la memoria histórica. Este pasado "puede ser reconstruido o reinventado, pero es conocido y apropiado por todos. Valorar, restaurar, proteger el patrimonio cultural es un indicador claro de la recuperación, reinvención y apropiación de una identidad cultural" (Molano, 2007: 84). Como toda construcción ideológica, la identidad ca mbia según los contextos culturales y las coyunturas sociales, "no hay identidades inmutables sino procesos sociales de identificación" (Bartolomé, 2006).

Frecuentemente, en esta dinamización se usan referentes identitarios tradicionales, a veces mitificados, pero básicamente resignificados, por ejemplo "la vestimenta, la culinaria, la lengua o los rituales colectivos, pasan a tener un nuevo significado al utilizarse como emblemas manifiestos de la identidad propia y contrapuesta a la de los otros sectores sociales" (Bartolomé, 2006: 32). 
Cuando parte del pueblo, como ha sucedido en Lambayeque, no se hace consciente de su pasado, no valora su cultura y olvida sus referentes identitarios tradicionales, las élites construyen de arriba a abajo una identidad sobre la base de la creación o recreación de mitos, héroes o líderes nacionales. "La característica de estas identidades es la autoadscripción del individuo al grupo por medio de la mímesis, la repetición (el eslogan), los ritos, el líder que da su nombre a la multitud anónima convertida en masa" (Paris Pombo, 1990: 81).

En las últimas décadas del siglo pasado, en Lambayeque se desarrollaron dos discursos de identidad colectiva que se fundamentaban en el renacer y en la revalorización de la cultura mochica. A continuación se analizan estos discursos.

El primero de ellos está basado en los trabajos que el antropólogo estadounidense Richard Schaedel desarrolló en Lambayeque a partir de la década de 1970. Schaedel se apoyó en los estudios etnográficos de Heinrich Brüning, quién residió en Lambayeque entre los años 1875 y 1925. Durante estos años recolectó miles deobjetos arqueológicos, hizo cientos de fotografías y realizó un valioso registro sonoro de los últimos pobladores que hablaban la lengua muchik ${ }^{2}$ (Yep, 2002; Vásquez, 2006). Sus grabaciones han sido herramientas imprescindibles para los antropólogos y lingüistas que estudian las comunidades rurales lambayecanas en busca de pruebas de la continuidad muchik (Brüning, 1922; Chávez, 2006).

Para Schaedel, los muchik eran un pueblo con entidad propia que habría continuado existiendo desde la etapa prehispánica hasta la actualidad. "La suya no sería una identidad reinventada, sino una identidad redescubierta, que había estado opacada durante décadas por un discurso homogeneizador basado en la idea del mestizo como paradigma de la identidad costeña" (Asensio, 2014: 100).

Su idea fundamental era la pervivencia de la cultura prehispánica, en las tradiciones y formas de vida de los pueblos costeros de Lambayeque. El establecimiento de la cultura incaica, española y criolla solo habría supuesto un barniz superficial, que no habría transformado su esencia mochica. Schaedel argumentaba que: "la tarea principal de los antropólogos que explotamos los datos de este pueblo, sea del pasado o del presente, es la de esforzarnos para que su situación mejore" (Schaedel, 1989: 8). Afirmaba que existía un continuo cultural desde los mochicas prehispánicos hasta los habitantes contemporáneos de la costa norte y, defendía la necesidad de conservar la identidad muchik con el fin de crear comunidades económicamente sostenibles; para ello, puso en marcha un proyecto de recuperación de las técnicas artesanales tradicionales, a las que denominaba paleotecnologías (Schaedel, 1987), y de la lengua muchik.

A partir de la década de 1990, Schaedel creó un movimiento neoindigenista cuyo objetivo era la revitalización de la cultura muchik, que según sus estudios permanecía viva en las costumbres y en el pensamiento de los habitantes de las zonas rurales de la costa norte de Perú (Schaedel, 1987).

En 1995, algunos discípulos de Schaedel, entre ellos el antropólogo peruano Víctor Rodríguez 
SuySuy, decidieron llevar su discurso al terreno político presentándose a las elecciones municipales en diferentes poblaciones (Alva Mendo, 2004). Las aspiraciones políticas de los seguidores de Schaedel finalizaron en un rotundo fracaso, ya que no ganaron en ninguna de las localidades donde se presentaron. Al año siguiente, Rodríguez SuySuy fundó la Confederación de los Pueblos Muchik como estrategia de activismo social (Maeda Ascencio, 2009). Pocos años después, continuando con la labor de Schaedel y de SuySuy, el antropólogo Jorge Sachún creó el Equipo Etnopedagógico Muchik, Quechua y Afro Richard Schaedel(EMUQA). Sachún, al igual que sus predecesores, defendía que la superación de la pobreza en Lambayeque pasaba por la reafirmación de su identidad cultural muchik y el acceso al control de los recursos y activos (Schaedel, 1987; Rodríguez SuySuy, 1997).

El segundo de los discursos de identidad colectiva fue elaborado por la élite regional, a raíz del descubrimiento de importantes restos arqueológicos en Lambayeque. Para conseguir el financiamiento de las excavaciones arqueológicas se estableció una alianza entre arqueólogos, empresarios regionales y el estado peruano. Esto permitió la creación de patronatos ${ }^{3}$, integrados por políticos y empresarios, que gestionaban directamente el dinero que llegaba de la cooperación internacional para sufragar los trabajos arqueológicos.

En este contexto, las élites políticas, empresariales y ciertos arqueólogos, potenciaron la creación de un nuevo discurso de identidad colectiva, identificándolo con los supuestos valores de los antiguos mochicas: 1) control de la producción agropecuaria,
2) jerarquización y orden social, y 3) desarrollo del comercio a media y larga distancia. Las élites, avaladas por las teorías de algunos arqueólogos, se presentaron ante la opinión pública como una alternativa al mundo andino y al poder limeño, ya que, según ellas, aportaban agroexportación, orden y seguridad a la región (Asensio, 2012). Este discurso fue creado de arriba hacia abajo, es decir, desde las élites económicas y políticas al pueblo (Expósito, 2017).

El gran desarrollo de la élite política y empresarial surgió gracias a la agroexportación, al establecimiento de los gobiernos regionales en el año 2002, y al gran aumento del turismo tras el descubrimiento del Señor de Sipán y de otros sitios arqueológicos. El descubrimiento del Señor de Sipán significó un antes y un después en la arqueología peruana y en la sociedad lambayecana, ya que debido al turismo se originó un impacto económico muy beneficioso para la población (Expósito, 2017). De esta forma, Lambayeque pasó vertiginosamente de un casi inexistente turismo, a ser uno de los destinos más frecuentados y demandados. Actualmente, el turismo en Lambayeque está "fuertemente vinculado a los descubrimientos arqueológicos y a la puesta en valor del patrimonio cultural prehispánico. Sin el auge del turismo, que legitima y abre la ventana de oportunidad política, la redefinición de los discursos identitarios no habría sido posible o al menos habría ocurrido de una manera y con un ritmo muy diferentes" (Asensio, 2012: 36).

En el año 2003 se inauguró en Lambayeque el Museo Tumbas Reales ${ }^{4}$, donde actualmente se exponen los restos del Señor de Sipán y el resto 
de los hallazgos encontrados en el sitio arqueológico de Huaca Rajada-Sipán. Este recinto se ha convertido en un referente regional y en el eje de todos los circuitos turísticos de la costa norte (Expósito, 2017).

En torno a las figuras del Señor de Sipán, y de su rico ajuar funerario, se ha creado toda una producción industrial y comercial. Se venden desde llaveros y camisetas con la representación de la orejera del gobernante, hasta libros que narran los misterios de la sociedad mochica. Numerosos espacios públicos lambayecanos están decorados con la iconografía muchik rescatada por la arqueología (Silverman, 2005). También han aparecido bares, restaurantes, e incluso una universidad, con el nombre del Señor de Sipán (Asensio y Trivelli, 2011).

Los seguidores de Schaedel argumentan que los museos construidos en las últimas décadas "son un instrumento de las elites regionales para apropiarse de su pasado prehispánico" (Asensio, 2014: 29). Por ello, proponen que pasen a manos municipales en lugar de estar gestionados por arqueólogos a los que se les “percibe como los principales enemigos del autorreconocimiento étnico de los pobladores rurales" (Asensio, 2014: 30).

En resumen, a finales del siglo XX coexistían dos discursos de identidad muchik en Lambayeque: uno nació con Schaedel, y en la actualidad continúa siendo defendido por sus escasos seguidores, centrando su trabajo en el desarrollo de las comunidades rurales; el otro, sustentado por los arqueólogos más prestigiosos y por las élites empresariales y políticas de la región, repercutió principalmente en las ciudades de Lambayeque.

Desde comienzos del siglo XXI se da un proceso de retroalimentación de ambos discursos (Asensio, 2014). Arqueólogos, políticos regionales y diferentes museos, tal y como demandaban Schaedel y sus seguidores, comenzaron a realizar, en las áreas rurales, planes de desarrollo social y proyectos para revalorar la cultura muchik. Como consecuencia de esta colaboración se empezó a utilizar el idioma muchik en las ceremonias oficiales, ganándose así terreno en la institucionalidad. En el año 2010 el gobierno regional aprobó una ordenanza 5 que establecía como objetivo a mediano plazo la enseñanza obligatoria del muchik en todas las escuelas de primaria y secundaria de la región. Sin embargo, a día de hoy esta ordenanza sigue sin cumplirse. Una escenificación de esta colaboración se produjo en el año 2009, en el marco del IV Reencuentro Macrorregional Muchik, donde se reunieron diferentes personalidades de la cultura y la política para trabajar conjuntamente por el bien del pueblo muchik (Asensio, 2014).

En la actualidad, el proceso de rescate de la cultura mochica y la construcción de la identidad muchik, se caracterizan por:

-La existencia de un pasado común: un sustrato mochica, que sería el origen de la identidad lambayecana.

- La continuidad genética mochica.

-La permanencia de la población en el territorio ancestral mochica. 
-La existencia de apellidos mochicas.

-La utilización y el deseo de aprender palabras del idioma muchik.

-La pervivencia de tradiciones culturales y tecnológicas mochicas.

•El orgullo de ser herederos de una gran civilización.

-La utilización de la cultura muchik como bien de mercado, dentro de una economía neoliberal.

-El uso simbólico de la iconografía mochica, tanto por las élites como por el pueblo.

-El deseo de rescatar, valorar y difundir la civilización mochica.

Como se ha visto, una característica fundamental de este proceso se basa en la continuidad histórica y cultural mochica, ya que "en Lambayeque se da un proceso de civilización que parte de Ventarrón, que sigue en Collud, luego en Sipán, prosigue en Chotuna, Pampa grande y Túcume y es convertido en las grandes reducciones de Zaña, Chiclayo y Lambayeque, ya en época colonial y que continúa hasta la actualidad. Son 5000 años de historia e identidad lambayecana" (Alva Meneses, comunicación personal, 2015).

Esta continuidad, se refleja en la pervivencia y uso de topónimos en diferentes distritos, antropónimos en apellidos lambayecanos, y en la utilización de palabras de origen mochica para referirse a ciertos alimentos. De esto se deduce que, pese al mestizaje, hay en la actualidad una fuerte presencia étnica y cultural mochica en la zona costera de la región (Elera, 2017). Esto se corroboró con los estudios de ADN que realizó el Proyecto Arqueológico Sicán, dirigido por el arqueólogo Carlos Elera. En este proyecto, se pudo verificar que los actuales apellidos Chapoñán, Llauce, Puémape, Ñamfuñay, Siesquén, Cajusol y Llontop, son de origen mochica. Según Elera, los moches y sus descendientes, los chimús y los caciques coloniales son, en realidad, la misma gente. Es decir, genéticamente, son un mismo pueblo que, a través del tiempo, ha ido cambiando cultural y políticamente (Elera, 2017).

Por otra parte, los investigadores Klaus Haagen y Manuel Tam (2009: 129) afirman que "la mayoría de la población del Sicán ${ }^{6}$ medio estaba compuesta por individuos étnicamente mochica descendientes de la cultura moche", y añaden que, "un sustrato mochica en el último complejo prehispánico del Valle de Lambayeque señala una persistencia única de identidad local, memoria cultural y conciencia práctica que sobrevivió a todos los sistemas políticos impuestos, incluido el Sicán" (Haagen y Tam, 2009: 132). Este sustrato mochica habría permanecido entre la población lambayecana bajo la superficie de las posteriores etapas culturales que se desarrollaron en la región, desde mediados del siglo VIII hasta mediados del siglo XVI (Haagen y Tam, 2009).

Respecto a las nociones biológicas y genéticas, en relación a los procesos de etnogénesis, considero que son un aporte para la investigación, pero en ningún caso, que son un factor determinante para la construcción identitaria; lo importante en estos procesos étnicos, es conocer cómo se siente y cómo 
se autopercibe una persona, independientemente de si su ADN indica que tiene un porcentaje alto o bajo de ancestría indígena. El ADN es insuficiente para determinar la pertenencia a un grupo étnico, ya que el factor cultural es crucial. De más está decir, que los estudios de ADN deben utilizarse con mucho cuidado, para evitar discursos racistas y políticas discriminadoras; deben utilizarse en beneficio de la población y no en detrimento de ésta.

Actualmente, en Chile se está ejecutando un proyecto de investigación (FONDECYT 1191948: "Estructura genética y continuidad ancestral de poblaciones originarias del Norte Chico: estudio genómico de ADN antiguo y actual"), que rrealizará pruebas de ADN a comunidades indígenas diaguitas para conocer su relación con los diaguitas precolombinos y, eventualmente, con otras etnias prehispánicas. En este sentido, y según las encuestas que se han realizado para abordar los posibles efectos que pudiera generar el conocimiento de su perfil genético de ancestría, en el proceso de etnogénesis y de construcción identitaria, se ha constatado que a muchas personas no les afectaría tener resultados contrarios a los esperados, o sea, baja ancestría diaguita, debido a que la mayoría de ellos, desde su infancia, han desarrollado una identidad diaguita, la que con el tiempo y, probablemente, con las políticas del Estado, se ha fortalecido.

En circunstancias parecidas, considero que en Lambayeque esto no ocurriría de la misma manera, ya que son pocas las personas que, desde su infancia, han desarrollado una identidad muchik; además, las políticas de Estado que promueven el fortalecimiento identitario, son mínimas.

Tanto Elera, como Haagen y Tam son ejemplos de un discurso que entrelaza las anteriores propuestas identitarias. Una muestra de ello es el trabajo que realiza Elera como director del Museo Nacional Sicán: "uno de los aspectos culturales más importantes del museo es ser un ente articulador que fortalezca la identidad mestiza de Ferreñafe, en particular la matriz étnica y cultural muchik" (Elera, 2006: 63). Elera, además, trabaja con el Comité de Gestión de los Bosques de Pómac y Patrimonio Cultural de la Provincia de Ferreñafe cuyos fines institucionales

"buscan primordialmente elevary mantener el nivel y calidad de vida de una comunidad responsable con el medio ambiente, teniendo como base el desarrollo de actividades sostenibles que se orienten a la agricultura, ganadería, apicultura y otras actividades productivas de carácter orgánico, así como el desarrollo en determinadas zonas de un turismo rural sostenible que beneficie a las poblaciones del lugar" (Elera, 2006: 63-64).

El objetivo es fortalecer la identidad étnica y cultural muchik, además de proteger el patrimonio y la biodiversidad de Lambayeque. Otro de los principales objetivos de este comité es representar a sus socios en temas que afecten a su desarrollo empresarial, aunando los intereses comunitarios y económicos. 


\section{Actual estado del proceso de reetnificación muchik}

Las actuales aproximaciones teóricas que han abordado las identidades étnicas, se pueden dividir en cuatro propuestas: 1) primordialistas, 2) constructivistas, 3) instrumentalistas, 4) interaccionistas (Bartolomé, 2006: 30).

La propuesta primordialista enfatiza "la intensidad de los lazos sociales grupales vividos como aspectos fundamentales en la constitución de la persona" (Bartolomé, 2006: 30). En esta perspectiva se incluyen aquellos que entienden la identidad étnica como "una extensión de las relaciones de parentesco, en la medida en que un grupo étnico tiende a asumir una ascendencia común y propone o cree compartir lazos de sangre" (Weber, 1979 [1922]; Keyes, 1982: 6, en Bartolomé, 2006: 30): los "pueblos sienten que su modo de ser está íntimamente ligado a la sangre, la raza, la lengua, la religión o a la tradición" (Geertz, 1987: 221) y estos serían sus "sentimientos primordiales".

Por otra parte, la propuesta constructivista enfatiza "en el carácter construido de las identidades de los grupos étnicos, en cuya constitución se evidencian tanto componentes históricos, lingüístico o culturales como imaginarios" (Bartolomé, 2006: 31). Se orienta principalmente hacia las dimensiones identitarias de la etnicidad más que a sus consecuencias políticas, y la considera como un fenómeno vinculado a la modernidad en un mundo de rápidos cambios (Bartolomé, 2006: 31).

La propuesta instrumentalista, percibe la identidad étnica básicamente como un recurso para la movilización política, "dentro de la cual es manipulada para obtener determinados fines" (Bartolomé, 2006: 32): los grupos étnicos funcionan como un grupo de interés (Glazer y Moyniham, 1975: 4), son una colectividad con intereses comunes, que manipulan sus formas culturales (parentescos, mitos, ritos, etc.) para competir o defender esos intereses (Cohen, 1982:308).

Por último, el enfoque generativo o interaccionista entiende al grupo étnico como "una forma de organización orientada a regular la interacción social a través de la presencia de fronteras a la interacción, a la vez que genera categorías de autoadscripción y de adscripción por otros" (Barth, 1976, en Bartolomé 2006: 34). Es un tipo organizacional cuyos referentes culturales son muy variables, por lo tanto, las identificaciones étnicas resultantes no están vinculadas necesariamente con un patrimonio cultural exclusivo. Las identidades construidas en estos grupos son relacionales, porque necesitan de otras para contrastarse (Bartolomé, 2006: 34).

Después de estudiar el proceso identitario muchik considero que se enmarca dentro de la propuesta constructivista, ya que se basa fundamentalmente en la recuperación histórica de la cultura moche, en la importancia lingüística del idioma muchik y en la puesta en valor de elementos culturales, tales como la danza y la artesanía, que funcionan como contraposición a la cultura inca-andina y limeña-criolla.

En este trabajo, para analizar en profundidad el proceso actual de construcción de la identidad muchik, el grado de autoadscripción a un grupo 
étnico de la población y además, verificar si existe un proceso de etnicidad y de etnogénesis, se realizaron diversas entrevistas a especialistas e informantes relevantes.

En una entrevista realizada a Ysaac Galán, Magíster en Investigación y Docencia, me afirmó que, en su opinión, sí existe una identidad muchik "que consiste, en aquellos elementos culturales, que conservan la herencia milenaria de los pueblos o culturas matrices prehispánicas de la costa norte de Perú, los cuales se sucedieron y convergieron para dar origen a lo que actualmente se denomina identidad muchik lambayecana" (Galán, comunicación personal, 2018).

Al conversar con Lady Vinces, licenciada en Ciencias de la Comunicación, acerca de la identidad muchik en Lambayeque, me indicó que:

“es verdad que 'lo muchik' o "lo moche” está muy de moda por los impresionantes hallazgos arqueológicos, pero considero que imponer una identidad desde el lado del estudio académico no ayuda, sino que lo convierte en una moda "gaseosa", y es, además, bastante básico porque solo se asocia: muchik-fuerza, lo que fuimos. Pero ahora ¿qué somos?, ¿qué queda?. Sólo el rostro y algunas técnicas y manifestaciones culturales que se catalogan como artesanales, nada más" (Vinces, comunicación personal, 2018).

Al preguntarle a Vinces si la identidad muchik se estaba utilizando como una estrategia de marketing para hacer negocios, ganar dinero o conseguir votos, contestó: “Así es, pero diles algo y te pegan. Ya me ha pasado. Todo es superficial"
(Vinces, comunicación personal, 2018). Por otra parte, el antropólogo Walther Maradiegue me expuso que:

“Cuando hablamos de 'lo moche', no estamos hablando ya de una cultura prehispánica que existió en un espacio temporal determinado, con sistemas políticos, económicos y culturales determinados que, muy probablemente, hayan desaparecido en el 800 d.C., sino que estamos ante una categoría histórica aglutinante de diversas culturas prehispánicas (Cupisnique, Salinar, Moche, Sicán, Chimú), que se desarrollaron en un territorio en común y que fueron superponiéndose en el poder político, aparentemente, de forma sucesiva" (Maradiegue, comunicación personal, 2018).

Según el arqueólogo Jorge Gamboa "la supuesta identidad moche regional norcosteña es, bajo un examen cuidadoso en el campo, un constructo altamente funcional al modelo socioeconómico vigente” (Gamboa, comunicación personal, 2018).

En este sentido, cuando le pregunté a Maradiegue por el proceso de construcción de la identidad muchik, lo señaló como

"un fenómeno ligado al neoliberalismo, entendido como un régimen cultural y económico vigente en el Perú desde la década de 1990, cuya inauguración simbólica hallé en el descubrimiento del llamado Señor de Sipán en 1987. La continuidad con el pasado no se remite, entonces, a ideales sociales de formación de estados-nación modernos, 
sino a la constitución de grupos sociales que aceptan einstrumentalizan la identificación colectiva, con el grupo étnico que alguna vez pobló la costa norte. Lo que resulta, dista de las concepciones tradicionales de la antropología acerca de los grupos étnicos $y$, en cambio, nos plantea alguna especie de etnicidad capitalista que denominamos lo Moche Inc."7 (Maradiegue, comunicación personal, 2018).

Maradiegue realizó una investigación antropológica, en Lambayeque, para su Tesis de Magíster. Durante el trabajo de campo acompañó a un artesano que fue llevado, junto a otros compañeros de profesión, a instalar puestos de venta de artesanía en el Gran Hotel de Chiclayo (Lambayeque), para la feria "Galería de la Identidad Lambayecana". Maradiegue le preguntó al artesano si le gustaba participar en esta actividad, a lo que respondió: "para mí es lo mismo estar aquí o estar en mi taller, al final es trabajo. Lo que me digan para decir yo les digo a estos" (Maradiegue, 2017: 91). A raíz de esta respuesta, Madariegue reflexiona:

“Obviamente es de suponer que ofrecer los productos a la sombra de este discurso es vital para lograr una buena venta, pero no estamos hablando solamente de una estrategia de marketing, sino de una expresión y celebración de una identidad cultural. Si nos limitáramos a tomarlo como un discurso de marketing, nos quedaríamos solamente en el producto en sí mismo, pero consideramos que aquí lo primero que se vende es el discurso de una identidad -la identidad del productor-, para luego vender los productos de esta identidad" (Maradiuegue, 2017: 91).

Considero que, en el actual proceso de construcción identitaria muchik, se está utilizando la cultura moche como un producto en venta que se ofrece a los turistas, tanto nacionales como extranjeros. Esto sucede debido a que Perú está regido por una lógica de economía de mercado neoliberal, donde lo que prima es conseguir beneficios económicos.

Coincido con Rancière, en que este fenómeno es cada vez más común en la actual era de capitalismo globalizado y, que determina la construcción de la identidad de los pueblos, normalizando la mercantilización de su otredad (Rancière, 2007). Considero que, en este contexto de neoliberalismo, existen individuos y comunidades étnicas muchik que intentan replicar, a su nivel, el funcionamiento comercial de las grandes corporaciones.

En cada lugar, los procesos identitarios dependen de dinámicas propias y particulares; en Lambayeque, la reinvención y construcción de la identidad Muchik, según me comunicó Guillermo Figueroa, profesor en las universidades Pedro Ruíz Gallo (Lambayeque) y Nacional de Frontera (Sullana), "satisface cierto nacionalismo medio hipócrita de la clase dominante, al regionalismo y al anticentralismo de una región en expansión como es la lambayecana" (Figueroa, comunicación personal, 2018).

En esta región, cada vez hay más voces críticas con la deriva que está tomando el proceso de construcción identitaria muchik. Conversando con Figueroa, me expuso que: 
"muchos arqueólogosy, sobre todo, las autoridades y medios de expresión practican un -orgullo moche- hipócrita, por ejemplo, con la moda de la elección de la-Iñikuk Muchik8-o con la publicación de diccionarios y manuales del idioma muchik, que sólo les da fama a las élites intelectuales. Estas propuestas no llegan a los campesinos, ni transforman nada" (Figueroa, comunicación personal, 2018).

Considero que, la identidad muchik está en pleno proceso de formulación, reinvención y construcción por parte de antropólogos y élites regionales. Pero, como he constatado en mi investigación, hay pobladores lambayecanos que no entienden este proceso ni se identifican con él.

\subsection{Grupo étnico muchik}

Un grupo étnico es una colectividad humana basada en la creencia de un origen común, real o imaginado, y con carácter organizativo (Cardoso de Oliveira, 2007). Es una "colectividad que se identifica a sí misma y que es identificada por los demás conforme a criterios étnicos (tales como el idioma, la religión, la tribu o la nacionalidad) y que comparte un sentimiento común de identidad con otros miembros del grupo" (Stavenhagen 1991: 3).

Al conversar con la doctora en administración de la educación, Medali Peralta, sobre la autoadscripción étnica de la población rural lambayecana, me expuso que:

“el pueblo no está enterado de que son mochicas, aunque tienen apellidos mochicas, rasgos mochicas y de que, algunas palabras que hablan, son muchik. Por ello, se habla de una falta de identidad cultural y en los colegios se puede apreciar más... si vemos del punto de vista de la población, el ser indígena es considerado casi como un insulto, de allí el llamado indio que era considerado inferior; si yo converso con algún poblador y le digo indígena se va sentir ofendido" (Peralta, comunicación personal, 2018).

Por su parte, según Ysaac Galán:

"Los pueblos de herencia muchik en la costa norte no son catalogados como «pueblos indígenas u originarios», a pesar de practicar costumbres prehispánicas. Incluso, muchos de ellos se reconocen como pueblos mestizos" (Galán, comunicación personal, 2018).

En la Ley peruana $N^{\circ} 28736$, para la protección de pueblos indígenas u originarios en situación de aislamiento y en situación de contacto inicial, promulgada en el 2006, se define como pueblos indígenas a las personas

"que se autoreconocen como tales, mantienen una cultura propia, se encuentran en posesión de un área de tierra y forman parte del Estado peruano conforme a la Constitución. En éstos se incluye a los pueblos indígenas en situación de aislamiento o en situación de contacto inicial”.

En el mapa de pueblos indígenas u originarios del Perú, se señala que: 
"Los pueblos indígenas u organizaciones son aquellos colectivos que descienden de poblaciones que vivían en el país desde antes de la época de la Colonia y que conservan todas o parte de sus instituciones sociales, económicas y políticas. Son además, aquellos grupos que se auto reconocen como parte de un colectivo distinto de la sociedad nacional" (Base de datos de pueblos indígenas $\mathrm{u}$ originarios, 2012).

En Perú, el Ministerio de Cultura ha identificado 55 pueblos indígenas u originarios. De ellos, 51 son originarios de la Amazonía y 4 de los Andes. Algunos antropólogos consideran a los pueblos de herencia muchik como indígenas, sin embargo "los mismos pobladores no se autodefinen como tales” (Galán, comunicación personal, 2018).

De acuerdo a lo anterior, considero que, en Lambayeque no se puede hablar, en la actualidad, de un grupo étnico muchik. Igualmente, considero que, si las comunidades rurales de la costa lambayecana tuvieran conciencia de pertenencia al grupo étnico muchik y se organizaran, estarían en condiciones de solicitar el reconocimiento como pueblo indígena u originario, ya que descienden de poblaciones que vivían en Lambayeque en la época precolonial, conservan tradiciones culturales y tecnológicas ancestrales, poseen apellidos mochicas y utilizan palabras del idioma muchik. Pero, insisto en que estas circunstancias hoy en día no se están dando.

\subsection{Etnogénesis muchik}

El proceso de construcción de la identidad muchik es todavía muy reciente y, en la actualidad, considero que está ralentizado o prácticamente estancado.

A continuación, se analizarán los conceptos de etnogénesis y de etnicidad, ya que son los más apropiados para estudiar los procesos de construcción y resurgimiento identitario que se están desarrollando, hoy en día, en Latinoamérica.

El concepto de etnogénesis ofrece una alternativa para explicar los fenómenos, cada vez más numerosos, de resurgimiento y de reivindicaciones identitarias en Latinoamérica (Luna, 2014). Un proceso de etnogénesis puede producir un doble cambio en la sociedad, tanto a nivel subjetivo de las formas de definición identitaria, como a nivel objetivo de las estructuras materiales (económicas y políticas). Estos cambios permiten la aparición de una "nueva identidad cuya estructura es distinta a la etnia originaria" (Boccara, 1999: 426). Una de las definiciones más utilizadas en los últimos años es la que proponen Bonté e Izard:

“el término etnogénesis, (...) se refiere a los procesos de reavivamiento o al surgimiento de una conciencia colectiva de grupos a menudo minoritarios. Esta forma de conocimiento de una pertenencia original $\mathrm{y}$, a veces, exclusiva puede basarse tanto en el uso de un lenguaje común (...) como en narraciones pseudohistóricas o rasgos fenotípicos. Cualquiera que sea el criterio seleccionado por los propios actores, uno de los elementos clave de esta concepción contemporánea de la etnogénesis parece 
ser la necesidad de demarcación o incluso oposición a otros grupos (dominantes)" (Bonté e Izard, 2008: 789).

Para Miguel Ángel Bartolomé la etnogénesis

"ha sido tradicionalmente utilizada para dar cuenta del proceso histórico de la configuración de colectividades étnicas, como resultado de migraciones, invasiones, conquistas o fusiones y también ha sido esgrimido para designar el surgimiento de nuevas comunidades que se designan a sí mismas en términos étnicos, para diferenciarse de otras sociedades o culturas que perciben como distintas a su autodefinición social" (Bartolomé, 2003: 174).

El concepto de etnogénesis se ha aplicado en los últimos 40 años en el estudio de procesos de identidades emergentes donde, muchas veces, los pobladores no se reconocían como indígenas, pero sí se evidenciaban vínculos con antiguos pueblos precolombinos. "Esta vinculación se da con elementos de cultura material, con actividades productivas, continuidad de parentesco, cosmovisionales y territoriales, esta última variable es determinante en el caso diaguita chilenos"9 (Molina y Campos, 2017: 126).

Según el investigador de la universidad de Utah Klaus Haagen, tras la llegada de los españoles a Lambayeque se produjo un proceso de etnogénesis:

"Los intentos relativamente exitosos para mantener las tradiciones e identidades locales pueden haber sido parte de una constelación de respuestas indígenas para amortiguar las consecuencias negativas del colonialismo. Si bien puede ser fácil considerar esto en términos de hibridación cultural o sinergia, la interacción entre Europa y el ritual andino, en Mórrope, fue probablemente más compleja. Sostengo que es un signo de etnogénesis, la creación de un nuevo tipo de identidad muchik en un momento de amplia discordia social y una amenaza externa que cambia los comportamientos culturales muchik que tuvieron un impacto en la estructura de su acervo genético" (Haagen, 2016: 123).

El proceso muchik es similar al del pueblo Manta ${ }^{10}$ (Ecuador) y al de los diaguitas de Chile, ya que una de las bases sobre las que fundamentaron sus demandas fue la presencia de esta población en un territorio que históricamente les ha pertenecido por permanencia y ancestralidad. Los diaguitas chilenos consiguieron su objetivo tanto interna como externamente (Bartolomé, 2006) ya que, en primer lugar, los pobladores se autoreconocieron como diaguitas y, posteriormente, en el año 2006, fueron reconocidos por el Estado chileno. Esta nueva identidad se construyó "en virtud de su historia indígena, sus apellidos vinculados a la lengua kakan (ya extinta) y su localización dentro de territorios considerados diaguitas en periodos prehispánicos" (Molina y Campos, 2017).

Aplico el concepto de etnogénesis en Lambayeque en relación al proceso que se ha desarrollado en los últimos 40 años en el marco del estudio de la identidad emergente muchik. En mi investigación he podido constatar que la mayoría de los 
pobladores no se reconocen como indígenas, pero sí evidencian vínculos con los antiguos pueblos precolombinos, tales como el uso de algunas palabras del idioma muchik, sus apellidos, sus técnicas pesqueras y agrícolas y sus recetas culinarias.

Según mi investigación, la identidad Muchik tiene un carácter procesal que cambia con el tiempo y las circunstancias, además, se manipula instrumentalmente y recurre a distintos signos diacríticos (elementos culturales) para definirse. Por otra parte, considero que si en Lambayeque se acelerara el proceso de etnogénesis muchik se producirían al menos dos cambios: uno a nivel subjetivo, de las formas de definición identitaria, y otro, a nivel material, reflejado en la economía y en la política regional.

Constaté que, en Lambayeque se construyó, hace varias décadas, un recuerdo idealizado de la historia regional. Esto se realizó entretejiendo el pasado y el presente como una memoria colectiva histórica, recomponiendo las tradiciones regionales y resignificando el etnónimo muchik.

Considero que, el proceso de etnogenesis muchik intenta, aunque muy débilmente en la actualidad, recuperar un pasado común, actualizarlo y asumirlo como suyo con el fin de construir un mejor presente y futuro para las comunidades descendientes de los muchik.

Por último, hay que tener en cuenta que, los procesos de etnogénesis se desarrollan en un amplio periodo de tiempo, y muchas veces, al analizarlos se ven como hechos evidentes, pero en su evolución sufren altibajos y estancamientos. En estos momentos, el proceso identitario muchik se encuentra en una etapa de ralentización, en todos los aspectos.

\subsection{Etnicidad muchik}

Durante la década de 1990, se puso en marcha un proceso de etnicidad muchik por el cual las reivindicaciones étnicas se incorporaron a la agenda política y mediática.

Bartolomé entiende la etnicidad "como una identidad en acción, como asunción política de la identidad" (Bartolomé, 2006: 29) y añade: "la identidad en acción, la etnicidad, supone siempre una orientación a fines, incluso la prosecución de dichos fines pueden modificar las características del grupo en cuestión, a través de faccionalismos o alianzas" (Bartolomé, 2006: 37).

En este sentido, la etnicidad surge cuando una identidad étnica pone en marcha una acción política. La identidad muchik fue prioritaria en la agenda de los políticos lambayecanos hasta fines de la década de 2010, sin embargo, en la actualidad, tal y como me indicó Luisa Santisteban, gestora cultural en la localidad de Morrope"1 "ya no es un asunto que entre en la campaña electoral. Así son los políticos, juegan con los sentimientos patrióticos de la gente. Si hay interés de la gente por construir identidad promoverán esta. En las anteriores elecciones se habló en los discursos sobre este tema, ahora no" (Santisteban, comunicación personal, 2018).

Luisa conoce el caso del pueblo diaguita de Chile, el cual, en el año 2006 consiguió ser reconocido 
por el gobierno chileno como grupo étnico originario. Al reflexionar con ella sobre si algo similar podría suceder con los muchik de Lambayeque me expresó que: "conozco a los diaguitas, pero aquí no ocurre eso, el Ministerio hizo su mapa de lenguas originarias y el muchik no está incluido. Los muchik no son considerados... iya están muertos!". Al comentarle que el idioma de los diaguitas también está extinto y que aún así se les había reconocido, gracias a la permanencia de sus apellidos y de sus costumbres, Luisa contestó: "estamos en Perú... es un proceso largo y todo depende de la voluntad política", y añadió "no somos considerados indígenas. Me parece que el antropólogo Jorge Sachún estuvo viendo eso, pero para el gobierno somos una comunidad costera". Pese a esto, Luisa no se resigna y cree que en Lambayeque "hay gente que está en la búsqueda de una identidad que sea propia del norte y que los diferencie de los Incas" (Santisteban, comunicación personal, 2018).

A principios del siglo XXI, el Gobierno Regional de Lambayeque reconoció la elección de la Iñikuk o Doncella muchik como "parte de la etnicidad muchik, símbolo de laboriosidad, hospitalidad, honestidad ancestral, y como representante de la belleza física y espiritual de la mujer muchik" (Gobierno Regional de Lambayeque, 2006). Sin embargo, hay mujeres en Lambayeque como, por ejemplo, Ninfa Idrogo (Investigadora del Taller de investigación en Ciencias Sociales TAICS-Perú) que consideran que:

“esta es una elección sin trascendencia, porque ellas no tienen responsabilidad social ni cultural. Las Iñikuk no tienen ni capacitación ni financiamiento para realizar tareas concretas en favor de las mujeres y los niños herederos de los moches. No hay actividades más allá de la elección, falta respaldo institucional y social" (Idrogo, comunicación personal, 2018).

Otro ejemplo de la puesta en marcha de políticas identitarias se observa en el documento "Memoria de Gestión 2003-2010 del Gobierno Regional de Lambayeque". Este documento promueve actividades institucionalizadas a favor de la identidad cultural muchik, como la primera declaración Étnico Cultural Muchik, que fue promovida por Rodríguez SuySuy, donde escolares de la Institución Educativa Santa Magdalena Sofía, por primera vez dieron el saludo de bienvenida en la desaparecida lengua muchik (Galán, 2018).

En el año 2007, el Gobierno Regional propuso festejar anualmente la Semana de la Identidad Muchik, en la cual se celebran diversas actividades de valoración cultural e incluye la participación de la población. Un año después se organizaron los “Reencuentros Macroregionales Muchik (La Libertad, Lambayeque, Piura y Tumbes) con el fin de intercambiar experiencias en la recuperación y vigorización de la identidad y reafirmar la vigencia y continuidad muchik” (Galán, 2018).

En el año 2010, el Consejo Regional de Lambayeque, a través del Acuerdo Regional No 079, aprobó la revaloración de la lengua muchik como un elemento necesario para lograr el reconocimiento oficial de la etnia muchik. 
En la actualidad, todas estas propuestas no han servido para que se enraíce en la sociedad lambayecana un verdadero y potente sentimiento de pertenencia a la etnia muchik. Tampoco han ayudado al surgimiento de organizaciones fuertes que revaloricen esta cultura y que propongan al gobierno regional o nacional su reconocimiento como pueblo indígena u originario.

En esta investigación he constatado que, actualmente, en Lambayeque no existen organizaciones sociales muchik fuertes, ni organismos políticos departamentales que trabajen por el reconocimiento de los descendientes de los mochicas, como parte de los pueblos originarios de Perú. Prueba de ello es que, en la actualidad, ya no se realizan los pocos encuentros muchik que existían, por ejemplo, los "Reencuentros étnicos muchik"12.

Según el arqueólogo Víctor Tullume, “aún no se ha logrado este ansiado deseo de reconocimiento que perseguían nuestros luchadores: el Dr. Richard Schaedel, Víctor Rodríguez SuySuy y otros" (Tullume, comunicación personal, 2018). Tullume lamenta que los líderes muchik hayan fallecido: "ahora quedamos sus continuadores. Somos líderes que luchamos por muchos años, incomprendidos...sin apoyo”. Aún así, sigue bregando por el mantenimiento y la difusión de la cultura muchik, y para que (la que considera, su etnia) sea reconocida por el gobierno de la región. Tullume es muy crítico con las élites políticas y empresariales lambayecanas: "Solo miran por sus intereses. Ni siquiera son parte de nuestro pueblo"; y más aún, con ciertos arqueólogos: "ellos son académicos, solo ven la parte arqueológica. Su apoyo en las comunidades no existe, exceptuando al arqueólogo Carlos Elera que sí se integra con los muchik" (Tullume, comunicación personal, 2018).

Medali Peralta es otra persona que trabaja por la difusión y el reconocimiento de la identidad muchik. Al respecto, me expuso que:

“en Lambayeque se está trabajando en talleres educativos y eventos en diferentes instituciones, y cada quién, según su criterio profesional, va rescatando, valorando y difundiendo el muchik, pero a nivel de las autoridades regionales, que son las que deben hacer un plan de trabajo, en la actualidad no hay nada sólido" (Peralta, comunicación personal, 2018).

En mi investigación he constatado que, en Lambayeque se ha estado dando un proceso de recuperación, o puesta en escena, de elementos culturales considerados tradicionales, sin embargo, para el antropólogo Pedro Alva, asesor del Gobierno Regional de Lambayeque: "No se nota todavía un discurso étnico, ni menos una propuesta política en base a ella. No contamos con una élite étnica que asuma este discurso" (Alva, comunicación personal, 2018). En este sentido, considero que es necesario reflexionar acerca de si no han existido esos líderes étnicos o, si es que a la élite política y empresarial lambayecana no les ha interesado tenerlos en cuenta, porque defienden los intereses de los pobladores más humildes.

Por todo lo expuesto, considero que en Lambayeque, actualmente, no existe una propuesta de acción política identitaria, por lo tanto, no hay un proceso 
de etnicidad ya que no hay un objetivo común para conseguir una mejora de las comunidades a través de demandas y reivindicaciones políticas indígenas. Durante mi investigación no se constató que, en la actualidad, haya una identidad étnica muchik que ponga en marcha una acción política en Lambayeque. Una de las razones por las que esto sucede es el descrédito que tiene la política en el país, y los políticos -muchos de ellos acusados de corrupción-, en Lambayeque.

Durante mi trabajo de campo no encontré organizaciones sociales muchik fuertes, ni organismos políticos departamentales que trabajen por el reconocimiento de los descendientes de los mochicas, como parte de los pueblos originarios de Perú.

Para finalizar este capítulo expondré que la situación actual en Lambayeque evidencia un panorama donde se aprecia que los discursos muchik de los líderes étnicos han perdido presencia e influencia en las instituciones respecto a la década pasada. Por esta razón, su intervención social, tal como sucedió en el pasado, se ha reducido a talleres y a pequeños eventos en las zonas rurales. "Esto significa volver a la estrategia que ya intentaron, sin mucho éxito, en la década de 1990" (Asensio, comunicación personal, 2019).

\section{Conclusiones}

A pesar de los recientes estudios que demuestran el continuum cultural y el sustrato étnico/ genético muchik en Lambayeque, el proceso de reetnificación y reivindicación de la identidad muchik se encuentra ralentizado. Como se expuso anteriormente, la identidad no es un concepto fijo, sino cambiante, por ello, los procesos de construcción de la identidad colectiva están siempre vivos y tienen sus propios ritmos; hay etapas en las que se aceleran y en otras se ralentizan. En las poblaciones descendientes de los mochicas no se han enraizado los discursos identitarios que, décadas pasadas, iniciaron antropólogos, por un lado, y arqueólogos y políticos, por otro. En estos momentos, esos discursos sirven para mantener una industria turística vinculada con la cultura mochica, para celebrar diferentes concursos (doncellas muchik, guerreros muchik, cocina, etc.) y para que algunos jóvenes aprendan unas cuantas palabras muchik en los cursos que se imparten en Chiclayo (capital de Lambayeque). Lamentablemente, los discursos identitarios no han ayudado a que las comunidades rurales o pesqueras se autoidentifiquen colectivamente como herederos de los mochicas y, como tales, reivindiquen sus derechos como pueblo originario.

Por otra parte, hay que reconocer el trabajo del arqueólogo Carlos Elera y su equipo, los cuales se preocupan por fortalecer la matriz étnica y cultural muchik en Lambayeque.

De acuerdo a lo analizado en este trabajo se puede concluir que en la actualidad la población lambayecana descendiente de los pueblos originarios no posee una identidad muchik, no se identifica ni se define como grupo étnico muchik, ni tampoco expresa una alteridad frente a otros grupos.

Actualmente en Lambayeque no se está dando un fuerte proceso de etnicidad, ya que no hay organizaciones que estén poniendo en acción su identidad étnica con el fin de conseguir una legitimación política, social y cultural. 
Lo que sí se puede observar es un intento por resignificar el concepto de "lo Moche", dentro de una economía de mercado capitalista con claros fines de lucro, a través de la turistificación y de la venta de productos culturales prehispánicos. La expresión “lo Moche" la utilizo como una categoría histórica aglutinante de diversas culturas y poderes políticos prehispánicos (Cupisnique, Salinar, Moche, Sicán, Chimú) que se desarrollaron en Lambayeque. En este sentido, lo fundamental para muchos lambayecanos es sacar un beneficio económico de los productos culturales indígenas.

Como se ha descrito, el proceso de etnogénesis muchik es similar a otros que se han desarrollado en Latinoamérica, como el de los Manta (Ecuador) y los diaguitas (Chile). Este grupo étnico, que se daba por desaparecido, cuya población tiene pocos rasgos indígenas (y una lengua extinta), tuvo que reconstruirse, autoidentificarse y organizarse para, posteriormente, reivindicar sus derechos como pueblo originario. Este caso debería servir de ejemplo a las comunidades muchik, sin embargo, en Lambayeque el proceso no fluye de la misma manera.

La construcción de una identidad es un proceso largo, la etnogénesis muchik lleva más de tres décadas en funcionamiento y lo apasionante de este fenómeno es que se está desarrollando en estos precisos momentos, con sus pugnas, sus acalorados debates, sus aciertos y errores, sus conquistas y sus derrotas, sus avances y estancamientos; en definitiva, es un proceso vivo, y su éxito depende de la voluntad de sus pobladores.

\section{Referencias citadas}

Alva, W. (2004): Sipán: Descubrimiento e Investigación, Lima, Edición del Autor.

Asensio, R. H. (2012): “Nosotros los muchik”, en Pérez Galán, B. y Asensio, R. H., eds., ¿El turismo es cosa de pobres? Patrimonio cultural, pueblos indígenas y nuevas formas de turismo en América Latina, Tenerife, ACA; PASOS, RTPC; Instituto de Estudios Peruanos.

Asensio, R. H. (2014): “Entre lo regional y lo étnico: el redescubrimiento de la cultura mochica y los nuevos discursos de identidad colectiva en la costa norte (19872010)”, en Cuenca, R. ed., Etnicidades en construcción. Identidad y acción social en contextos de desigualdad, Lima, Instituto de Estudios Peruanos.

Asensio, R. H. y C. Trivelli (2011): “Dinámicas territoriales rurales con identidad cultural, Valle Sur-Ocongate (Cusco, Perú)”, en Hernández Asensio, R. y Arista Zerga, A., eds., Turismo, museos y desarrollo rural ¿Por quiény para quién?, Documento de Trabajo, 163. Serie Estudios sobre el Desarrollo, 1, Lima, IEP, RIMISP.

Bartolomé, M. A. (2003): “Los pobladores del Desierto. Genocidio, etnocidio y etnogénesis en la Argentina", Cuadernos de Antropología Social, 17, 2003, pp. 163-189,

Bartolomé, M. A. (2006): "Los laberintos de la identidad. Procesos identitarios en las poblaciones indígenas", Avá, Revista de Antropología, 9, pp. 28-48.

Boccara, G. (1999): "Etnogenesis mapuche: resistencia y restauración entre los indígenas del centro-Sur de Chile (siglos XVI-XVIII)", The Hispanic American Historial Review, 79 (3), pp. 425-461. 
Bonté, P.y M. Izard (2008): Dictionnaire de l'ethnologie et de l'anthropologie, Paris, Press universitaires de France.

Brüning, H. (1922): Estudios monográficos del departamento de Lambayeque, Fascículos I-IV, Lima, Gráfica Pacific Press.

Disponible en web: https://terraeantiqvae.com/m/ discussion?id=2043782\%3ATopic\%3A35108

Cardoso de Oliveira, R. (2007): Etnicidad y estructura social, Centro de Investigaciones y Estudios Superiores en antropología Social / Universidad Autónoma Metropolitana / Universidad Iberoamericana.

Elera, C. (2006): Casos de gestión cultural en el Perú, Lima, Instituto Nacional de Cultura del Perú.

Elera, C. (2017): “El quehacer institucional del Museo Nacional de Sicán en la cuenca de La Leche, Lambayeque", Quingnam, 3, pp: 35-60.

Expósito, J. (2017): “Impacto medioambiental, turístico y social del descubrimiento del Señor de Sipán en Lambayeque", M+A. Revista Electrónica de Medioambiente, 18 (1), pp. 1-25.

Haagen, K. (2016): “Vida y muerte en el Perú colonial: inicios de la bioarqueología en Lambayeque histórico (1536-1750 d.C.)", Boletín de arqueología PUCP, 20, pp. 103-128.

Haagen, K. y M. Tam (2009): Surviving Contact: Biological Transformation, Burial, and Ethnogenesis in the Colonial Lambayeque Valley, North Coast Peru, en: K. J. Knudson y C. M. Stojanowski (eds.), Bioarchaeology andidentity in the Americas, 126-152, University Press of Florida, Gainesville.

Hernández-Ramírez, M.y E. Ruiz-Ballesteros (2011): "Etnogénesis como práctica. Arqueología y turismo en el pueblo manta (Ecuador)", AIBR. Revista de Antropología Iberoamericana, 6 (2), mayo-agosto, 2011, pp. 159-191.

Luna Penna, G. (2014): “Trayectoria crítica del concepto de etnogénesis", Logos: Revista de Lingüística, Filosofía y Literatura, [S.l.], v. 24, n. 2, p. 167-179.

Maeda Ascencio, J. (2009):"Richard Schaedel y los Muchik. Biografía del más grande muchikólogo del área andina", Revista electrónica Terrae Antiquae. Red social de Arqueólogos e Historiadores, s/n.

Disponible en web: https://terraeantiqvae.com/forum/ topics/richard-schaedel-y-los-muchik

Maradiegue Montaño, W. (2017): Construcción de la tradición en el norte del Perú: "lo moche" como performance y gobermentalidad, Tesis de magíster inédita, Pontificia Universidad Universidad Católica del Perú, Lima.

Mercado Maldonado, A. y A. V. Hernández Oliva (2010): "El proceso de construcción de la identidad colectiva", Convergencia, 53, pp. 229-251.

MINCETUR (2017): Registro de visitantes a los Museos de Lambayeque en el año 2017, Lima, MINCETUR.

Molano, O. L. (2007): "Identidad cultural que evoluciona”, Revista Opera, 7, pp. 69-84.

Molina, R y L. Campos (2017): “Confín geográfico, refugio indígena, pueblo de indios y etnogénesis en 
el Huasco Alto, (Chile)", Revista de Geografía Norte Grande, 68: 123-140 (2017).

Paris Pombo, M. D. (1990): Crisis e identidades colectivas en América Latina, México, Plaza y Valdés.

Schaedel, R. (1987): “Dos mil años de continuidad cultural de los Muchik en la costa del Perú”, Iberoamerikanisches Archiv, 13, pp. 117-123.

Schaedel, R. (1989):“Discurso en ceremonia de apertura del "Centro de Investigación y Promoción del Pueblo Muchik"; Moche, Perú, 7/08/89, p. 8.

Silverman, H. (2005): “Embodied Heritage, Identity Politics, and Tourism", Anthropology and Humanism, 30 (2), pp. 141-155.

Stavenhagen, R. (1991): "Los conflictos étnicos y sus repercusiones en la sociedad internacional”, Revista Internacional de Ciencias Sociales, XLIII (1), pp. 117-131. Disponible en: https://unesdoc.unesco.org/ark:/48223/ pf0000088113_spa

Rancière, J. (2007): El desacuerdo. Política y filosofía, Buenos Aires, Nueva Visión.

Rodriguez SuySuy, V. (1997): Los pueblos Muchik en el mundo andino de ayer y siempre, Moche, Centro de Investigación y promoción de los pueblos Muchik, "Josefa SuySuy Azabache".

Torero, A. (1986): "Deslindes lingüísticos en la costa norte peruana”, Revista Andina, Centro de Estudios Rurales andinos "Bartolomé de Las Casas" 4(2), pp. 523-548.
Vásquez, Ch. (2006): "El registro musical de Brüning”, en Folclor, cultura e identidad:ponencias del XVII Congreso Nacional y VI Congreso Internacional de Folclor Mildred Merino de Zela , Lima, pp. 275-283.

Yep, V. (2002): “Música peruana en cilindros de cera (1910-1925): las grabaciones musicales de Enrique Brüning”, Boletín de Lima, 130, pp. 11-17.

\section{Notas}

1 La cultura Mochica (también llamada Moche) fué una civilización que se desarrolló en los valles de la costa norte del Perú entre los años 100 y 850 d.C. Su desarrollo se fundamentó en el uso de los recursos marítimos y en la agricultura.

2 Según Fernando de la Carrera, autor del Arte de la lengua yunga, en 1644 más de cuarenta mil personas hablaban muchik en Lambayeque (Torero, 1986).

3 Los Patronatos Culturales son instituciones privadas creadas para contribuir al desarrollo del país; promueven y trabajan de la mano con el Estado en proyectos culturales de largo plazo, a nivel nacional e internacional, y en la recuperación del patrimonio cultural material e inmaterial de Perú, con el propósito de poner en valor su riqueza cultural, el civismo y la identidad nacional.

4 Durante el año 2016 alcanzó un total de 184.717 visitantes, una cifra récord de visitas desde que el museo inició su funcionamiento, hace catorce años, superando en más del $18 \%$ la cifra registrada en el 2015, de 156.605 visitas (MINCETUR, 2017). En el primer trimestre del 2017 fue el recinto peruano que más visitantes registró (El Comercio, 23.12.2017) 
5 Ordenanza regional 011-2010.

6 La cultura Sicán o Lambayeque se desarrolló en la costa norte de Perú, entre los valles de Motupe, al norte, y Jequetepeque, al sur, en el Departamento de Lambayeque. Fue clasificada por el arqueólogo Izumi Shimada en tres fases: Sicán Temprano (700 -900 d.C), Sicán Medio (900-1100 d.C.) y Sicán Tardío (1100 -1350 d.C.).

7 Este término se basa en las propuestas de John L. Comaroff y Jean ComarofF (2011) donde exponen numerosos ejemplos de etnicidades mercantilizadas y analizan la diferencia entre la construcción de la identidad, como persona jurídica o ideal, y la transformación de la cultura en mercancía, en la actual era neoliberal.

8 La Iñikuk (o doncella Muchik) es un concurso realizado en los colegios de Lambayeque donde se elige a una joven que represente los valores y tradiciones de la cultura mochica. Estos concursos se resignifican a partir del año 2003, convirtiéndose en un acto de afirmación y exaltación de la identidad neo-muchik. En el año 2006, el gobierno regional de Lambayeque convirtió los concursos de elección de Iñikuk, en una actividad obligatoria en todos los centros educativos de la región (RER no 161-2006-GRLAMB/PR, ratificado por la RDRS No 0675-2008-GR. LAMB/DREL).

9 Los diaguitas son el último pueblo indígena reconocido por el Estado de Chile, en el año 2006, trece años de la promulgación de la Ley Indígena 19.253. El territorio delimitado por los ríos Copiapó, por el norte, y Choapa, por el sur, zona conocida como Norte Chico, fue donde habitaron históricamente los diaguitas chilenos, cuya cultura floreció en el siglo XII.
10 Hernández-Ramírez y Ruiz-Ballesteros (2011) utilizan el término etnogénesis para referirse a un proceso que se está dando en el pueblo Manta de Ecuador y que es similar al que se desarrolla en Lambayeque, ya que a las dos comunidades se les daba prácticamente por desaparecidos y apenas se les reconocían rasgos indígenas.

11 Mórrope se ha autoproclamado como el último rincón de la cultura Mochica, porque a pesar de los siglos transcurridos, sus costumbres y tradiciones aún perduran; esto se debe a que su población ha estado libre de los flujos migratorios de los últimos años, gracias a su ubicación en medio del desierto, algo alejada del resto de la región.

12 Según exponía el Gobierno Regional de Lambayeque, el objetivo de esta actividad era "promover la continuidad de nuestra etnia muchik y el interca mbio cultural entre los pueblos del norte, enlazados por la misma historia y costumbres". El año 2009 se celebró el último Reencuentro Étnico Muchik. 